CLINICAL STUDY

\title{
Combined expression of BUB1B, DLGAP5, and PINK1 as predictors of poor outcome in adrenocortical tumors: validation in a Brazilian cohort of adult and pediatric patients
}

\author{
Maria Candida B V Fragoso ${ }^{1}$, Madson Queiroz Almeida ${ }^{1}$, Tania L Mazzuco ${ }^{3}$, Beatriz M P Mariani ${ }^{1}$, Luciana P Brito $^{1}$, \\ Talita Cardoso Gonçalves ${ }^{1}$, Guilherme A Alencar ${ }^{1}$, Lorena de O Lima ${ }^{1}$, Andre M Faria ${ }^{1}$, Isabelle Bourdeau ${ }^{3}$, \\ Antonio M Lucon ${ }^{2}$, Daniel S Freire ${ }^{1}$, Ana Claudia Latronico ${ }^{1}$, Berenice B Mendonca ${ }^{1}$, Andre Lacroix ${ }^{3}$ and \\ Antonio M Lerario ${ }^{1}$ \\ ${ }^{1}$ Unidade de Suprarrenal, Laboratório de Hormônios e Genética Molecular/LIM42 da Disciplina de Endocrinologie Metabologia, Hospital das Clínicas da \\ Faculdade de Medicina da Universidade de São Paulo, Avenida Dr Eneas de Carvalho Aguiar 155, 20 andar, Bloco 6, CEP: O5403900 São Paulo, Brazil and \\ ${ }^{2}$ Divisão de Urologia, Hospital das Clínicas, Faculdade de Medicina da Universidade de São Paulo, São Paulo, Brazil and ${ }^{3}$ Department of Medicine, Centre de \\ Recherche du Centre hospitalier de l'Université de Montréal (CRCHUM), Québec, Canada
}

(Correspondence should be addressed to M C B V Fragoso; Email: mariafragoso@uol.com.br)

\begin{abstract}
Background: A recent microarray study identified a set of genes whose combined expression patterns were predictive of poor outcome in a cohort of adult adrenocortical tumors (ACTs). The difference between the expression values measured by qRT-PCR of DLGAP5 and PINK1 genes was the best molecular predictor of recurrence and malignancy. Among the adrenocortical carcinomas, the combined expression of BUB1B and PINK1 genes was the most reliable predictor of overall survival. The prognostic and molecular heterogeneity of ACTs raises the need to study the applicability of these molecular markers in other cohorts.

Objective: To validate the combined expression of BUB1B, DLGAP5, and PINK1 as outcome predictor in ACTs from a Brazilian cohort of adult and pediatric patients.

Patients and methods: BUB1B, DLGAP5, and PINK1 expression was assessed by quantitative PCR in 53 ACTs from 52 patients -24 pediatric and 28 adults (one pediatric patient presented a bilateral asynchronous ACT).

Results: DLGAP5-PINK1 and BUB1B-PINK1 were strong predictors of disease-free survival and overall survival, respectively, among adult patients with ACT. In the pediatric cohort, these molecular predictors were only marginally associated with disease-free survival but not with overall survival. Conclusion: This study confirms the prognostic value of the combined expression of BUB1B, DLGAP5, and PINK1 genes in a Brazilian group of adult ACTs. Among pediatric ACTs, other molecular predictors of outcome are required.
\end{abstract}

European Journal of Endocrinology 166 61-67

\section{Introduction}

Adrenocortical tumors (ACTs) are common neoplasms with a prevalence of at least $3 \%$ in a population over the age of 50 years (1). Adrenocortical carcinoma (ACC) is a rare and aggressive malignancy, with a 5 -year survival lower than $35 \%$ in most populations (2). In adults, the differential diagnosis between an adrenocortical adenoma (ACA) and a localized ACC rely on the presence of at least three of nine histological Weiss criteria (3). However, in some cases, the diagnosis of malignancy is not straightforward. ACCs in children and adolescents constitute only $0.2 \%$ of all pediatric malignancies $(4,5)$. A remarkably high annual incidence of ACTs has been reported in children younger than 15 years from
Southern Brazil, where a high prevalence of a germline mutation of the TP53 tumor suppressor (p.R337H) was identified $(6,7)$. In contrast to adults, pediatric ACTs with apparently poor prognosis based on the histopathological features often have a better clinical outcome (8).

ACTs are heterogeneous neoplasms with incompletely understood pathogenesis. Different transcriptome analyses confirmed IGF 2 overexpression in the majority of adult ACCs $(9,10)$. In contrast, a single microarray analysis of pediatric ACTs did not discriminate ACAs and ACCs using unsupervised clustering (11). IGF2 and FGFR4 were similarly expressed in both benign and malignant pediatric ACTs $(11,12)$. Interestingly, IGF1R gene, whose product mediates the mitogenic effects 
of IGF2, was overexpressed in metastatic pediatric ACCs $(12,13)$.

Recently, de Reyniès et al. (14) identified genes in a microarray study that robustly discriminated adult ACAs and ACCs and identified two clusters of ACCs with distinct outcomes. They identified and validated that the combined expression levels of three genes were strong predictors of overall survival and disease-free survival. Accordingly, the difference between the expression values of discs large associated protein 7 (DLGAP5) and PTEN-induced putative kinase 1 (PINK1; $\Delta C_{\mathrm{T}}$ DLGAP5- $\Delta C_{\mathrm{T}}$ PINK1) was a strong predictor of recurrence and malignancy and the difference between the expression values of budding uninhibited by benzimidazoles 1 homolog beta $(B U B 1 B)$ and PINK1 $\left(\Delta C_{\mathrm{T}} B U B 1 B-\Delta C_{\mathrm{T}}\right.$ PINK1) was a reliable predictor of overall survival (14). These new molecular markers identified in a European population of patients may provide important predictors for the diagnosis and the management of adult ACTs. However, it needs to be validated in other groups of adult patients and studied in pediatric ACTs, whose molecular pathogenesis is clearly different from adult tumors (5).

In the current study, we investigated the prognostic value of the combined expression of DLGAP5, BUB1B, and PINK1 genes in an adult cohort of Brazilian patients with ACTs. In addition, we examined for the first time whether the same molecular markers can predict outcome in pediatric ACTs.

\section{Materials and methods}

The study was approved by the Ethics Committee of the Hospital das Clinicas, Sao Paulo, Brazil, and informed written consent was obtained from all patients and/or parents. Clinical and pathological data were retrospectively recorded. The study cohort consisted of 52 patients ( 24 pediatric and 28 adults) evaluated in our Institution from 1990 to 2010 (see Tables 1 and 2). The mean follow-up period in pediatric and adult groups was 80.4 and 65.8 months respectively. Endocrine work-up was performed in all patients.

In the pediatric group, 20 out of 24 cases were classified as ACC according to Weiss criteria (Weiss score $\geq 3$ ). However, only eight patients presented an advanced tumor stage (MacFarlane III or IV) at diagnosis and/or poor clinical outcome. Among adult ACTs, 14 cases were classified as ACAs (Weiss score <3) and 14 as ACCs (Weiss score $\geq 3$ ). Metastases were diagnosed by systematic imaging investigations mainly abdominal and chest computed tomography (CT) scans; bone scintigraphy in appropriated cases, magnetic resonance imaging, and more recently in selected cases with positron emission CT scan. All patients were submitted to unilateral adrenalectomy except one pediatric patient who presented a bilateral asynchronous ACT (15). Histopathological diagnosis, tumor weight, size, and Weiss scores were determined for each tumor specimen. Death related to ACC progression occurred in five pediatric and nine adult patients, within

Table 1 Clinical and molecular data of pediatric adrenocortical tumor patients.

\begin{tabular}{|c|c|c|c|c|c|c|c|c|c|c|c|}
\hline Patient & Sex & $\begin{array}{c}\text { Age } \\
\text { (years) }\end{array}$ & $\begin{array}{l}\text { Size } \\
(\mathrm{cm})\end{array}$ & Stage $^{a}$ & Weiss & $\begin{array}{l}\text { BUB1- } \\
\text { PINK1 }\end{array}$ & $\begin{array}{c}\text { DLGAP5- } \\
\text { PINK1 }\end{array}$ & $\begin{array}{l}\text { Recurrence/ } \\
\text { metastasis }\end{array}$ & $\begin{array}{c}\text { DFS } \\
\text { (months) }\end{array}$ & $\begin{array}{l}\text { Out- } \\
\text { come }\end{array}$ & $\begin{array}{c}\text { Follow-up } \\
\text { (months) }\end{array}$ \\
\hline 1 & $\mathrm{~F}$ & 0.90 & 6.00 & II & 3 & 8.2390 & 7.9830 & No & 99.00 & Alive & 99.00 \\
\hline 3 & $F$ & 1.25 & 3.70 & I & 5 & 3.9733 & 4.3300 & No & 24.80 & Alive & 24.80 \\
\hline 4 & $\mathrm{~F}$ & 1.58 & 4.00 & I & 3 & 3.5567 & 6.6150 & No & 26.15 & Alive & 26.15 \\
\hline 6 & $M$ & 1.72 & 4.00 & I & 4 & -1.8467 & -0.3433 & No & 164.10 & Alive & 164.10 \\
\hline 7 & $M$ & 2.00 & 6.50 & II & 4 & 0.0740 & -2.7520 & No & 174.00 & Alive & 174.00 \\
\hline 9 & $F$ & 2.00 & 5.00 & I & 4 & -0.3690 & 0.7790 & No & 84.00 & Alive & 84.00 \\
\hline 10 & $\mathrm{~F}$ & 2.08 & 4.00 & I & 4 & -1.2450 & -1.3540 & No & 79.00 & Alive & 60.00 \\
\hline 11 & $F$ & 2.10 & 3.00 & I & 1 & -1.5480 & 0.3840 & No & 148.00 & Alive & 148.00 \\
\hline 13 & $\mathrm{~F}$ & 2.42 & 3.80 & I & 5 & -1.3717 & 1.0333 & No & 74.60 & Alive & 74.60 \\
\hline 14 & $F$ & 2.44 & 2.50 & I & $\mathrm{N} / \mathrm{A}$ & 5.4767 & 6.7067 & No & 72.40 & Alive & 72.40 \\
\hline 15 & $\mathrm{~F}$ & 2.52 & 5.20 & II & 7 & -1.9200 & 1.1100 & No & 100.77 & Alive & 100.77 \\
\hline 16 & M & 2.59 & 2.00 & I & 5 & 4.3000 & 5.6300 & No & 155.83 & Alive & 155.83 \\
\hline 17 & $\mathrm{~F}$ & 2.87 & 3.50 & I & 2 & 0.9760 & 0.4740 & No & 167.17 & Alive & 167.17 \\
\hline 20 & $\mathrm{M}$ & 4.88 & 8.50 & III & 6 & -1.0883 & 1.6583 & On follow-up & 15.00 & Alive & 127.97 \\
\hline 21 & $\mathrm{~F}$ & 6.07 & 7.00 & II & 7 & -2.2100 & 0.6633 & On follow-up & 10.00 & CRD & 15.80 \\
\hline 22 & $\mathrm{~F}$ & 9.32 & 6.00 & IV & 7 & -1.5883 & 0.1117 & At diagnosis & - & CRD & 15.33 \\
\hline 23 & $M$ & 9.41 & 4.50 & I & 2 & 6.7530 & 6.7770 & No & 96.00 & Alive & 96.00 \\
\hline 25 & $\mathrm{~F}$ & 15.17 & 20.00 & IV & 7 & -1.1400 & 0.9333 & At diagnosis & - & CRD & 21.50 \\
\hline 26 & $\mathrm{~F}$ & 16.70 & 4.00 & I & 3 & 6.1733 & 8.0100 & No & 25.20 & Alive & 25.20 \\
\hline 27 & $\mathrm{~F}$ & 17.20 & 15.00 & II & 4 & 5.0800 & 5.7830 & No & 115.00 & Alive & 115.00 \\
\hline 28 & $M$ & 17.32 & 9.00 & III & 5 & 3.4550 & 11.2000 & No & 60.00 & Alive & 60.00 \\
\hline 29 & $\mathrm{~F}$ & 17.47 & 10.00 & IV & 8 & -0.9110 & -2.7570 & At diagnosis & - & CRD & 6.93 \\
\hline
\end{tabular}

DFS, disease-free survival; CRD, cancer-related death.

according to MacFarlane system. 
Table 2 Clinical and molecular data of adult adrenocortical tumor patients.

\begin{tabular}{|c|c|c|c|c|c|c|c|c|c|c|c|}
\hline Patient & Sex & $\begin{array}{c}\text { Age } \\
\text { (years) }\end{array}$ & $\begin{array}{l}\text { Size } \\
(\mathrm{cm})\end{array}$ & Stage $^{a}$ & Weiss & $\begin{array}{l}\text { BUB1- } \\
\text { PINK1 }\end{array}$ & $\begin{array}{l}\text { DLGAP5- } \\
\text { PINK1 }\end{array}$ & $\begin{array}{l}\text { Recurrence/ } \\
\text { metastasis }\end{array}$ & $\begin{array}{c}\text { DFS } \\
\text { (months) }\end{array}$ & $\begin{array}{l}\text { Out- } \\
\text { come }\end{array}$ & $\begin{array}{c}\text { Follow-up } \\
\text { (months) }\end{array}$ \\
\hline 30 & $\mathrm{~F}$ & 19.00 & 13.00 & III & 8 & -2.4760 & -3.2280 & On follow-up & 8.00 & CRD & 10.00 \\
\hline 31 & $\mathrm{~F}$ & 22.00 & 13.00 & IV & 7 & -0.5133 & 1.3000 & At diagnosis & - & CRD & 12.00 \\
\hline 32 & $\mathrm{~F}$ & 22.44 & 14.50 & II & 8 & -1.6100 & -0.5800 & On follow-up & 1.00 & CRD & 15.00 \\
\hline 33 & $\mathrm{~F}$ & 22.81 & 6.00 & III & 5 & 1.9060 & -0.7210 & On follow-up & 4.00 & Alive & 14.77 \\
\hline 34 & $\mathrm{~F}$ & 22.82 & 14.00 & IV & 6 & 1.3833 & 3.2200 & At diagnosis & - & CRD & 15.20 \\
\hline 35 & $\mathrm{~F}$ & 23.54 & 4.00 & I & 2 & 4.2733 & 7.4500 & No & 28.40 & Alive & 28.40 \\
\hline 36 & $\mathrm{~F}$ & 24.00 & 3.00 & I & 2 & 6.0620 & 4.9720 & No & 159.00 & Alive & 159.00 \\
\hline 37 & $\mathrm{~F}$ & 26.00 & 5.50 & II & 1 & 6.2310 & 6.2500 & No & 64.00 & Alive & 64.00 \\
\hline 38 & $\mathrm{~F}$ & 26.88 & 2.50 & i & 2 & 7.5200 & 9.3233 & No & 90.97 & Alive & 90.97 \\
\hline 41 & $\mathrm{~F}$ & 28.88 & 12.00 & IV & 4 & -7.3617 & -2.5000 & At diagnosis & - & CRD & 28.30 \\
\hline 42 & $\mathrm{~F}$ & 29.00 & 5.00 & I & 0 & 7.6050 & 7.1930 & No & 160.00 & Alive & 160.00 \\
\hline 43 & $M$ & 29.61 & 19.00 & IV & 8 & -4.1533 & -1.1867 & At diagnosis & - & CRD & 8.00 \\
\hline 44 & $\mathrm{M}$ & 30.00 & 9.60 & III & 4 & 0.2250 & -3.0130 & On follow-up & 4.00 & CRD & 12.00 \\
\hline 45 & $\mathrm{~F}$ & 30.48 & 12.00 & III & 6 & -0.2467 & 1.7267 & On follow-up & 4.00 & CRD & 12.00 \\
\hline 46 & $\mathrm{~F}$ & 35.00 & 2.00 & I & 3 & 5.3330 & 6.6650 & No & 102.00 & Alive & 102.00 \\
\hline 47 & $\mathrm{~F}$ & 35.56 & 3.00 & I & 0 & 7.5833 & 9.3633 & No & 54.12 & Alive & 54.17 \\
\hline 48 & $\mathrm{~F}$ & 35.73 & 6.00 & II & 1 & 1.7767 & 4.0000 & No & 121.43 & Alive & 121.43 \\
\hline 50 & $\mathrm{~F}$ & 37.60 & 2.50 & I & 2 & 7.3200 & 9.7267 & No & 202.83 & Alive & 202.83 \\
\hline 51 & $\mathrm{~F}$ & 39.00 & 2.50 & 1 & 0 & 5.7280 & 6.0770 & No & 93.00 & Alive & 93.00 \\
\hline 52 & $\mathrm{~F}$ & 41.00 & 2.80 & 1 & 1 & 5.1300 & 4.6500 & No & 143.00 & Alive & 143.00 \\
\hline 53 & $\mathrm{~F}$ & 41.36 & 1.80 & 1 & 0 & 6.4667 & 8.2000 & No & 43.17 & Alive & 43.17 \\
\hline 54 & $\mathrm{~F}$ & 43.45 & 18.00 & IV & 8 & 3.1400 & 5.4233 & At diagnosis & - & CRD & 35.37 \\
\hline 56 & $\mathrm{~F}$ & 45.19 & 10.00 & III & 7 & 7.7883 & 10.5417 & No & 128.50 & Alive & 128.50 \\
\hline 57 & $\mathrm{~F}$ & 47.00 & 3.50 & I & 1 & 8.1600 & 7.4840 & No & 84.00 & Alive & 84.00 \\
\hline 58 & $\mathrm{~F}$ & 47.69 & 5.00 & I & 0 & -11.9350 & -3.7350 & No & 79.30 & Alive & 79.30 \\
\hline 59 & $M$ & 54.00 & 4.50 & 1 & 4 & 6.9690 & 7.2920 & No & 25.00 & Alive & 25.00 \\
\hline 62 & $\mathrm{~F}$ & 64.06 & 3.50 & I & 0 & 6.5500 & 8.0783 & No & 45.97 & Alive & 45.97 \\
\hline 63 & $\mathrm{~F}$ & 65.32 & 6.00 & II & 4 & 2.6667 & 4.2567 & No & 54.73 & Alive & 54.73 \\
\hline
\end{tabular}

DFS, disease-free survival; CRD, cancer-related death.

${ }^{a}$ According to MacFarlane system.

a mean time of 15.67 months (6.9-35.4) after the diagnosis. The germline TP53 mutation p.R337H was studied in 21 pediatric and 20 adult patients. In pediatric patients, it was identified in $13(62 \%)$. In adults, two patients $(10 \%)$ were carriers of TP53 p.R337H germline mutations in heterozygous state (6).

\section{RNA extraction and quantitative real-time PCR}

Total RNA was extracted from the frozen tumor fragments stored in liquid nitrogen using TRIzol (Invitrogen) reagent method. The RNA integrity and concentration were evaluated by agarose gel electrophoresis (1\%) and spectrophotometry. cDNA was generated using the High Capacity cDNA Archive kit for RT (Applied Biosystems, Foster City, CA, USA). Quantitative real-time PCR was performed in the ABI PRISM 7000 Sequence Detector using TaqMan gene expression assays (Applied Biosystem). The assay IDs were BUB1B, Hs00177821_m1; PINK1, Hs00260868_m1; and DLGAP5, Hs007323_m1. A cycle threshold $\left(C_{\mathrm{T}}\right)$ value in the linear range of amplification was selected for each sample in triplicate and normalized to human beta glucuronidase (GUSB) endogenous control gene (4326320E). The differences of
$\Delta C_{\mathrm{t}}\left(\Delta C_{\mathrm{T}}\right.$ DLGAP5- $\Delta C_{\mathrm{T}}$ PINK1) and $\left(\Delta C_{\mathrm{T}}\right.$ BUB1B- $-C_{\mathrm{T}}$ $P I N K 1)$ were correlated with clinical and pathological parameters.

\section{Statistical analyses}

All statistical analyses were performed with the MedCalc Software (version 11.6.1.0; MedCalc Software BVBA, Brussels, Belgium). The adjusted cutoff values for $\left(\Delta C_{\mathrm{T}} \quad\right.$ DLGAP5- $\Delta C_{\mathrm{T}}$ PINK1) and $\left(\Delta C_{\mathrm{T}} \quad B U B B 1-\Delta C_{\mathrm{T}}\right.$ PINK1) were established by the receiver operating characteristic (ROC) curve method (see below). Univariate analysis was performed using Kaplan-Meyer curves and log-rank test statistics for comparison. A $P$ value $<0.05$ was considered significant.

\section{Results}

\section{DLGAP5-PINK1 and disease-free survival}

According to de Reyniès et al. (14), the subtraction of expression level of DLGAP5 and PINK1 (DLGAP5PINK1) in ACTs could discriminate between malignant and benign tumors and was a predictor of disease-free survival. Accordingly, a sample is predicted to be 
malignant if (DLGAP5-PINK1) <6.95. To find out whether similar results could be achieved in our cohort, we performed a Kaplan-Meyer survival analysis applying the same cutoff value to 23 adult patients with no evidence of residual disease or metastasis after surgery (absence of metastatic disease on preoperative evaluation and R0 surgical excision). All patients who remained disease free were followed for at least 24 months. The difference in disease-free survival between the two groups (DLGAP5-PINK $<6.95$ and DLGAP 5-PINK $\geq 6.95$ ) was significant (log-rank $P=0.0315$ ). However, the performance of the molecular marker was apparently inferior to a Weiss score $>2$ in prognosis prediction $(\log -\operatorname{rank} P=0.0016$; Fig. 1A). We wondered whether applying a different cutoff value would improve the discriminative performance of the molecular marker. To select the best possible cutoff for our adult cohort, we applied the ROC curve analysis method. To build up the curve, we divided the 28 adult patients in two groups: i) unfavorable outcome (metastasis on diagnosis or recurrent/metastatic disease on follow-up; $n=10$ ) and ii) favorable outcome (patients with no evidence of recurrence/metastasis after at least 24 months of follow-up; $n=18$ ). The greatest area under the curve (AUC) value was obtained with a cutoff of $\leq 3.22\left(\mathrm{AUC}=0.922, P=1.25 \times 10^{-12}\right)$. This optimized cutoff value defined two groups of patients with significantly different disease-free survival (log-rank $P=6.12 \times 10^{-6}$; Fig. 1B).

The next question was whether the molecular predictor was also discriminative in a pediatric cohort. To address this issue, we applied the adult cohort optimal cutoff value of $\leq 3.22$ to a cohort of 21 pediatric patients with no evidence of residual disease after surgery. We observed a marginally significant difference in disease-free survival (log-rank $P=0.0629$ ). Adjusting the cutoff value for the pediatric cohort did not improve its performance (log-rank $P=0.0629$; Fig. 1D). As previously reported, in pediatric patients, a Weiss score $>2$ is not a reliable predictor of malignancy (Fig. 1C).

\section{BUB1B-PINK1 as a predictor of overall survival in ACCs}

de Reyniès et al. (14) have demonstrated that the combined expression of BUB1B-PINK1 was the best predictor of overall survival in a cohort of histologically malignant ACTs. Accordingly, a sample was predicted to have a poor prognosis if (BUB1B-PINK1) $<6.32$. Applying the same cutoff values to 14 adult patients with histologically indeterminate or malignant ACTs (Weiss score $\geq 2$ ), we could observe two groups with distinct survival time (log-rank $P=0.037$ ). However, this molecular predictor was outperformed by the MacFarlane staging (log-rank $P=0.007$; Fig. $2 A$ ). To select the best possible cutoff for (BUB1B-PINK1) in our adult cohort, we applied the ROC curve analysis method
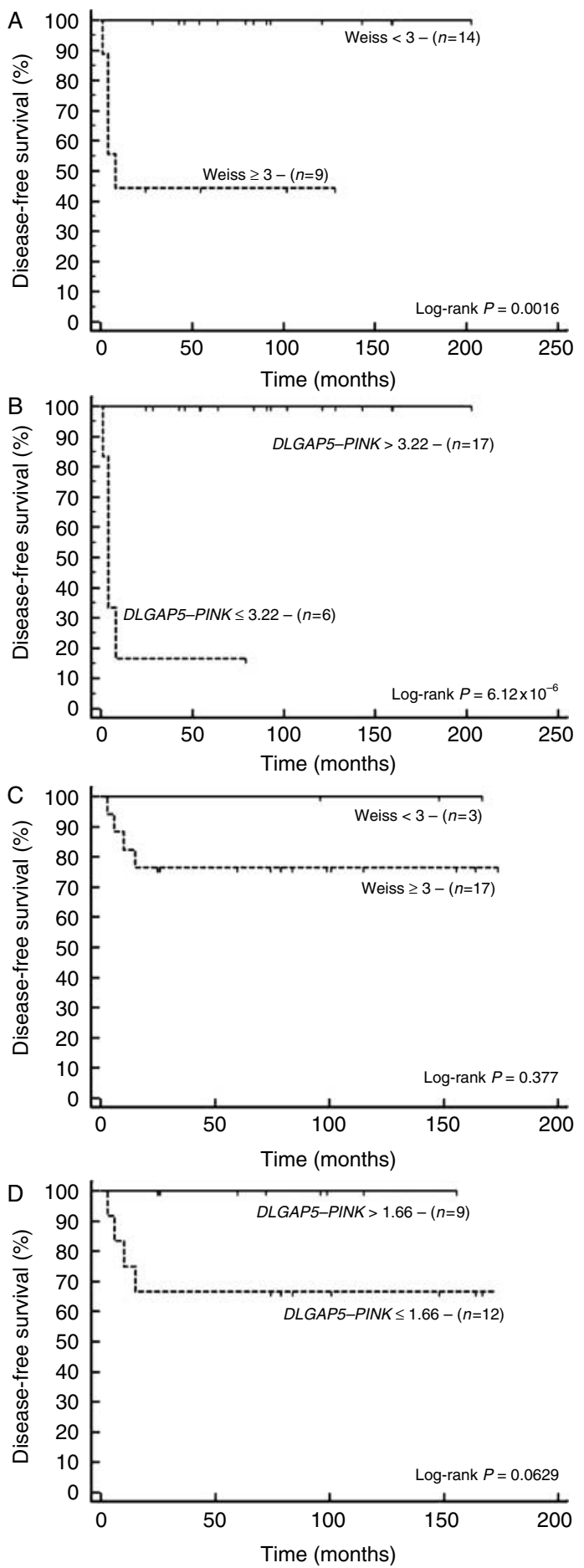

Figure 1 DLGAP5-PINK1 as a predictor of disease-free survival. In 23 adult patients with no evidence of residual disease after surgery, a sample is predicted to present a poor outcome if the subtraction of $C_{\mathrm{t}}$ values of DLGAP5-PINK1 is $<3.22$. The molecular predictor of malignancy was at least as accurate as Weiss score (panels $A$ and B). Among 21 pediatric patients, both the Weiss score and the molecular predictor could not discriminate groups with different outcomes, even after adjusting the cutoff for the best possible performance (panels $C$ and D). 
as described in the previous section. All patients that did not present an adverse outcome were followed for at least 60 months in this analysis. The greatest AUC value was obtained with a cutoff of $\leq 3.14$ (AUC $=0.907$, $P=1.07 \times 10^{-6}$ ). This adjusted cutoff value leads to a better prediction of overall survival (log-rank $P=4.56 \times 10^{-4}$; Fig. 2B). In the pediatric cohort with histologically indeterminate or malignant ACTs $(n=19)$, however, this molecular predictor was not associated with a statistically significant difference in overall survival, even after adjusting for the best possible cutoff value (log-rank $P=0.146$; Fig. 2D). In the pediatric group, tumor stage remains the only significant parameter associated with overall survival (log-rank $P=0.015$; Fig. 2C).

\section{Discussion}

ACC is a rare neoplasm with a dismal prognosis. Although the main prognostic factor is tumor stage, even localized disease (MacFarlane I and II) has a high relapse rate. The differential diagnosis between localized ACCs and adenomas is crucial and relies on a score of histological features (Weiss score), which has important drawbacks. To overcome the limitations of Weiss score, in the last few years, many authors have recently searched for molecular markers of malignancy. Among these, unsupervised hierarchical clustering of gene expression signatures has provided new insights into the identification of different groups of ACCs with distinct outcomes $(14,16)$. Giordano et al. (16) showed that cluster analysis revealed two subtypes of ACCs that reflected tumor proliferation, as measured by mitotic counts and cell cycle genes. de Reyniès et al. (14) also identified a subclassification of ACC based on the gene expression profile. Therefore, these two microarraybased assessment studies demonstrated that molecular signatures can robustly predict poor outcome with higher accuracy than morphological parameters $(14,16)$. However, these studies are difficult to perform and, consequently, unsuitable to the clinical practice. To overcome this limitation, de Reyniès et al. (14) identified three genes for which the combined expression values were highly associated with outcomes. According to their data, the difference in the expression values of DLGAP5-PINK1 and BUB1B-PINK1 were strong predictors of recurrence and overall survival, respectively, in adult ACT patients. DLGAP5 and BUB1B are overexpressed in ACCs. The former is involved in stem cell pluripotency and carcinogenesis $(17,18)$ and the latter controls mitotic checkpoint and chromosomal segregation during mitosis $(18,19)$. PINK1 gene, which is regulated by the PTEN gene and is involved with mitochondrial integrity, was found to be downregulated in ACTs (20). The authors suggested that due to its accuracy and simplicity, these molecular predictors would be relevant to clinical practice.
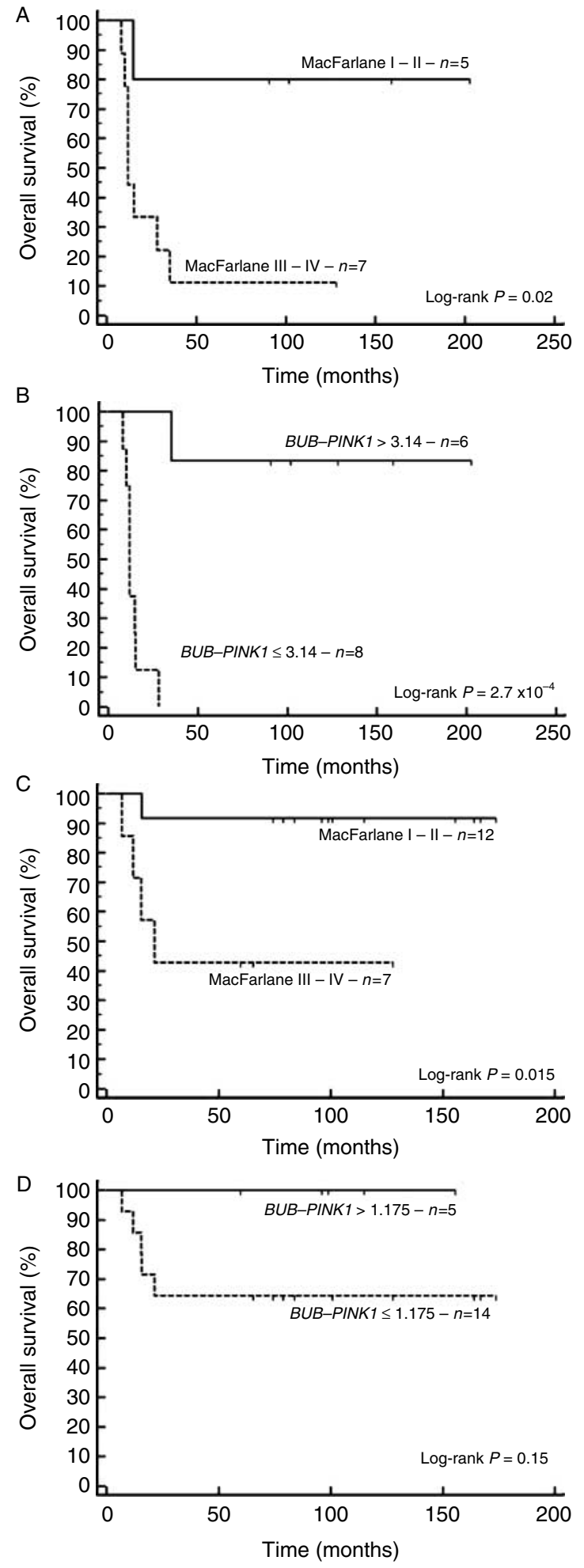

Figure 2 BUB1B-PINK1 as a predictor of overall survival. Among 14 adult $A C T s$ with a potentially malignant histology (Weiss $\geq 2$ ), the difference between expression values of BUB1B and PINK1 $\leq 3.14$ was at least similar to MacFarlane staging in predicting a fatal outcome (panels A and B). Among 19 pediatric patients, however, only staging was associated to a fatal outcome. 


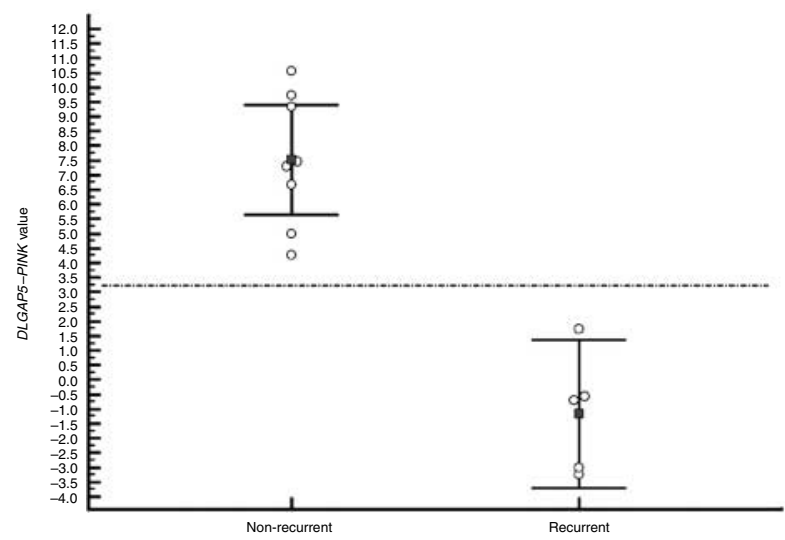

Figure 3 DLGAP5-PINK1 in 13 adult ACCs in which a R0 resection could be achieved. A cutoff value of 3.22 (dashed line) correctly classified all cases as 'recurrent' or 'non-recurrent'. Open circles: individual values; Filled squares: Mean values. Error bars: $95 \% \mathrm{Cl}$.

In order to validate these findings, we studied the expression values of the same genes in ACTs from Brazilian patients. In the adult cohort, our results were quite similar as those reported (14), in which the molecular markers were strong predictors of recurrence and survival, with an accuracy at least comparable to clinical and histological parameters, if not better. It is noteworthy that five out of 13 cases of our adult cohort with a Weiss score $\geq 2$ and R0 tumor resection presented a relapse on follow-up. The molecular predictor (DLGAP5-PINK1) $\leq 3.22$ correctly identified all cases as 'non-recurrent' and 'recurrent' (Fig. 3). In spite of the limited number of cases, these data are promising, suggesting that the molecular marker goes beyond clinical and histological information in prognosis prediction.

The differences in cutoff values of DLGAP5-PINK1 and $B U B 1 B-P I N K 1$ between our study and those reported by de Reyniès et al. (14) may be related to methodological issues. Nevertheless, external validation is important when there is inter-tumor heterogeneity; notably, both studies corroborate the reliability of these molecular markers in the clinical evaluation of adult ACT. In addition, we first employed these new molecular markers to predict outcome in a cohort of pediatric ACTs diagnosed in Brazilian patients. In this group of patients, these molecular markers were not good discriminators of outcome, although a marginally significant trend could be observed in disease-free survival curves (Fig. 1D).

In conclusion, we validated the prognostic value of the combined expression of BUB1B, DLGAP5, and PINK1 genes in a different group of adult ACTs and reinforced its potential applicability to clinical practice. For pediatric patients, according to our data, these molecular markers are still lacking sufficient discriminatory efficiency and other markers need to be identified.

\section{Declaration of interest}

The authors declare that there is no conflict of interest that could be perceived as prejudicing the impartiality of the research reported.

\section{Funding}

Conselho Nacional de Desenvolvimento Científico e Tecnológico (CNPq 200069/2009-8) from São Paulo, Brasil, and Laboratory of Endocrine Pathophysiology, Centre de Recherche du CHUM (CRCHUM), Canada.

\section{References}

1 Barzon L, Sonino N, Fallo F, Palu G \& Boscaro M. Prevalence and natural history of adrenal incidentalomas. European Journal of Endocrinology 2003149 273-285. (doi:10.1530/eje. $0.1490273)$

2 Allolio B \& Fassnacht M. Clinical review: adrenocortical carcinoma: clinical update. Journal of Clinical Endocrinology and Metabolism 200691 2027-2037. (doi:10.1210/jc.2005-2639)

3 Weiss LM, Medeiros LJ \& Vickery AL Jr. Pathologic features of prognostic significance in adrenocortical carcinoma. American Journal of Surgical Pathology 198913 202-206. (doi:10.1097/ 00000478-198903000-00004)

4 Sandrini R, Ribeiro RC \& DeLacerda L. Childhood adrenocortical tumors. Journal of Clinical Endocrinology and Metabolism 199782 2027-2031. (doi:10.1210/jc.82.7.2027)

5 Almeida MO \& Latronico AC. The molecular pathogenesis of childhood adrenocortical tumors. Hormone and Metabolic Research 200739 461-466. (doi:10.1055/s-2007-981476)

6 Ribeiro RC, Sandrini F, Figueiredo B, Zambetti GP, Michalkiewicz E, Lafferty AR, DeLacerda L, Rabin M, Cadwell C, Sampaio G, Cat I, Stratakis CA \& Sandrini R. An inherited p53 mutation that contributes in a tissue-specific manner to pediatric adrenal cortical carcinoma. PNAS 200198 9330-9335. (doi:10.1073/pnas. 161479898)

7 Latronico AC, Pinto EM, Domenice S, Fragoso MC, Martin RM, Zerbini MC, Lucon AM \& Mendonca BB. An inherited mutation outside the highly conserved DNA-binding domain of the p53 tumor suppressor protein in children and adults with sporadic adrenocortical tumors. Journal of Clinical Endocrinology and Metabolism 200186 4970-4973. (doi:10.1210/jc.86.10.4970)

8 Wieneke JA, Thompson LD \& Heffess CS. Adrenal cortical neoplasms in the pediatric population: a clinicopathologic and immunophenotypic analysis of 83 patients. American Journal of Surgical Pathology 200327 867-881. (doi:10.1097/00000478200307000-00001)

9 de Fraipont F, El Atifi M, Cherradi N, Le Moigne G, Defaye G, Houlgatte R, Bertherat J, Bertagna X, Plouin PF, Baudin E, Berger F, Gicquel C, Chabre O \& Feige JJ. Gene expression profiling of human adrenocortical tumors using complementary deoxyribonucleic acid microarrays identifies several candidate genes as markers of malignancy. Journal of Clinical Endocrinology and Metabolism 200590 1819-1829. (doi:10.1210/jc.20041075)

10 Giordano TJ, Thomas DG, Kuick R, Lizyness M, Misek DE, Smith AL, Sanders D, Aljundi RT, Gauger PG, Thompson NW, Taylor JM \& Hanash SM. Distinct transcriptional profiles of adrenocortical tumors uncovered by DNA microarray analysis. American Journal of Pathology 2003162 521-531. (doi:10.1016/ S0002-9440(10)63846-1)

11 West AN, Neale GA, Pounds S, Figueredo BC, Rodriguez Galindo C, Pianovski MA, Oliveira Filho AG, Malkin D, Lalli E, Ribeiro R \& Zambetti GP. Gene expression profiling of childhood adrenocortical tumors. Cancer Research 200767 600-608. (doi:10.1158/00085472.CAN-06-3767)

12 Almeida MQ, Fragoso MC, Lotfi CF, Santos MG, Nishi MY, Costa MH, Lerario AM, Maciel CC, Mattos GE, Jorge AA, 
Mendonca BB \& Latronico AC. Expression of insulin-like growth factor-II and its receptor in pediatric and adult adrenocortical tumors. Journal of Clinical Endocrinology and Metabolism 200893 3524-3531. (doi:10.1210/jc.2008-0065)

13 Doghman M, El Wakil A, Cardinaud B, Thomas E, Wang J, Zhao W, Peralta-Del Valle MH, Figueiredo BC, Zambetti GP \& Lalli E. Regulation of insulin-like growth factor-mammalian target of rapamycin signaling by microRNA in childhood adrenocortical tumors. Cancer Research 201070 4666-4675. (doi:10.1158/ 0008-5472.CAN-09-3970)

14 de Reynies A, Assie G, Rickman DS, Tissier F, Groussin L, ReneCorail F, Dousset B, Bertagna X, Clauser E \& Bertherat J. Gene expression profiling reveals a new classification of adrenocortical tumors and identifies molecular predictors of malignancy and survival. Journal of Clinical Oncology 200927 1108-1115. (doi:10.1200/JCO.2008.18.5678)

15 Lima Lde O, Lerario AM, Alencar GA, Brito LP, Almeida MQ, Domenice S, Latronico AC, Mendonca BB \& Fragoso MC. Clinical and molecular aspects of a pediatric metachronous adrenocortical tumor. Arquivos Brasileiros de Endocrinologia $e$ Metabologia $2011 \quad 55 \quad 72-77$. (doi:10.1590/S0004-273020 $11000100010)$

16 Giordano TJ, Kuick R, Else T, Gauger PG, Vinco M, Bauersfeld J, Sanders D, Thomas DG, Doherty G \& Hammer G. Molecular classification and prognostication of adrenocortical tumors by transcriptome profiling. Clinical Cancer Research $2009 \mathbf{1 5}$ 668-676. (doi:10.1158/1078-0432.CCR-08-1067)

17 Gudmundsson KO, Thorsteinsson L, Sigurjonsson OE, Keller JR, Olafsson K, Egeland T, Gudmundsson S \& Rafnar T. Gene expression analysis of hematopoietic progenitor cells identifies Dlg7 as a potential stem cell gene. Stem Cells 200725 1498-1506. (doi:10.1634/stemcells.2005-0479)

18 Assie G, Guillaud-Bataille M, Ragazzon B, Bertagna X, Bertherat J \& Clauser E. The pathophysiology, diagnosis and prognosis of adrenocortical tumors revisited by transcriptome analyses. Trends in Endocrinology and Metabolism 201021 325-334. (doi:10. 1016/j.tem.2009.12.009)

19 Wang Q, Liu T, Fang Y, Xie S, Huang X, Mahmood R, Ramaswamy G, Sakamoto KM, Darzynkiewicz Z, Xu M \& Dai W. BUBR1 deficiency results in abnormal megakaryopoiesis. Blood 2004103 1278-1285. (doi:10.1182/blood-2003-06-2158)

20 Unoki M \& Nakamura Y. Growth-suppressive effects of BPOZ and EGR2, two genes involved in the PTEN signaling pathway. Oncogene 200120 4457-4465. (doi:10.1038/sj.onc.1204608)

Received 24 May 2011

Accepted 27 October 2011 